Article

\title{
Dark Participation
}

\author{
Thorsten Quandt \\ Department of Communication, University of Muenster, 48143 Muenster, Germany; \\ E-Mail: thorsten.quandt@uni-muenster.de
}

Submitted: 2 April 2018 | Accepted: 25 May 2018 | Published: 8 November 2018

\begin{abstract}
Citizen participation in the news-making process has been a hopeful promise since the 1990s. Observers hoped for a rejuvenation of journalism and democracy alike. However, many of the enthusiastic theoretical concepts on user engagement did not endure close empirical examination. Some of the major fallacies of these early works (to whom the author contributed himself) will be outlined in this article. As a bleak flip side to these utopian ideas, the concept of "dark participation" is introduced here. As research has revealed, this type of user engagement seems to be growing parallel to the recent wave of populism in Western democracies. In a systematization, some essential aspects of dark participation will be differentiated. Finally, the benefits of (also) looking at the wicked side of things will be discussed.
\end{abstract}

\section{Keywords}

citizen engagement; dark participation; fake news; news-making process; participatory journalism; populism; propaganda; user-generated content

\section{Issue}

This article is part of the issue "News and Participation through and beyond Proprietary Platforms in an Age of Social Media", edited by Oscar Westlund (Oslo Metropolitan University, Norway) and Mats Ekström (University of Gothenburg, Sweden).

(C) 2018 by the author; licensee Cogitatio (Lisbon, Portugal). This article is licensed under a Creative Commons Attribution 4.0 International License (CC BY).

\section{Visions and Bitter Realities: Citizen Engagement in the News-Making Process}

Save Journalism! I remember a dear colleague wearing a shirt with that slogan at a conference sometime during the early 2000s. And, if I remember correctly, I wore the exact same shirt at the very same conference, as he had a full set of these with him. There was a certain heroic and noble Samaritan attitude connected to wearing it, and it also felt a little bit "punk" - or at least as punk as academics at conferences dare to be between conference cookies and presentation marathons. We wanted to save something important, a societal institution that seemed to be falling apart both economically and democratically.

This feeling of urgency, paired with excitement and hope for a new beginning, was not uncommon at that time. For the younger generation of journalism researchers, "legacy" media seemed to be stuck in completely crystallized traditions and was awfully outdated, especially in contrast to the exciting new things developing on the Internet. These hungry academics turned their attention to online journalism, a phenomenon that was still very much emerging and seemed very promising, as it allowed for totally new forms of storytelling and involved users as partners in the news-making process (Bowman \& Willis, 2003; Deuze, 2003; Pavlik, 2001). The very word "users" felt revolutionary, as the older generation of academics still thought of them as "recipients" who swallowed whatever the media machine spit out (Schönbach, 1997, 2001). As an added bonus, the online journalists themselves were young and hungry, so there was a kind of mutual generational understanding. In some ways, the upcoming new breed of journalism researchers might have seen themselves reflected in the online journalists; they also tried to inject innovative ideas into an established, but sluggish, system working against a notable vis inertiae to set it in motion again.

Indeed, initial resistance made the lives of this pioneer generation of online journalists quite hard. Established journalists from print, radio, and TV news didn't take their online colleagues seriously; some even detested the change and hoped it would simply go away. 
Equally, politicians, public relations officers, and other stakeholders largely ignored the "new kids on the block"; there were stories of online journalists not even being admitted to press conferences, being seated somewhere in the back, or being perceived as "computer nerds" (Deggerich, 2001a, 2001b). However, this situation changed rather quickly in just a few years. With the economic struggles of the parent media, the exodus of classifieds to online services, the mainstream adoption of Internet use, and the respective growth of use time, online journalism became accepted and even took over the lead role in many ways beyond the obvious production speed (e.g., Allan, 2006; Bivens, 2008; Hermida, 2010).

Despite (or maybe because of) this success story, the reality of participatory online news some 15 years later is very different from the early visions; notable forms of "produsage" (Bruns, 2008) and user-generated content seem to be largely missing from professional journalistic websites. The comment sections of online news media are flooded with hateful messages, opinion mongering, and incivility (e.g., Coe, Kenski, \& Rains, 2014; Harlow, 2015; Neurauter-Kessels, 2013; Santana, 2014). And what's worse, there are even presumed cases of strategic manipulation attempts of community sections by foreign states and related actors (Elliott, 2014). Some observers even regard this as a new information war happening in the guise of user participation (Erjavec \& Kovačič, 2012; Zelenkauskaite \& Balduccini, 2017). As a result, many news media restricted user participation or even gave up their comment sections altogether. Notable examples are Reuters, Bloomberg, The Guardian (certain topics), Stern (Germany), De Volkskrant (Netherlands), News24 (South Africa), and The Moscow Times (Russia). While non-proprietary platforms, like Facebook, Youtube, Instagram or Twitter, may offer an alternative route for news distribution and participation, as compared to comment sections controlled by the media themselves, the negativity and toxic atmosphere there can be equally bad, and multiple studies imply that the deliberative quality is even lower, as is the interaction with journalists who seem to neglect such channels even when they are officially supported by their media (Esau, Friess \& Eilders, 2017; Hille \& Bakker, 2013; Rowe, 2015; Su et al., 2018).

Broadly speaking, the idea of free, high-quality usergenerated content in the context of professional online news media is seemingly half dead. Naturally, there are promising projects outside traditional news outlets, but often these are driven by activists' interests in specific topics or they are small-scale, profit-driven news or PR ventures (as is often the case with online influencer channels on social media or special-interest blogs).

So, what went wrong? Maybe not much beyond human beings and societal reality not following some enthusiastic and rather utopian ideas. As I will discuss in this article, the issue predominantly lies with false expectations. Media managers' economic fantasies of a willing, free workforce were equally misguided as the rather naïve academic notions of a revitalized journalism in di- rect debate with its active users; both sacrificed empirical realism for fantasies that were driven by their own goals and hopes resulting in either a greedy or an idealistic projection (Section 2). As an antidote, I will propose and systematize the concept of "dark participation" - the evil flip side of citizen engagement (Section 3). This deconstruction of earlier, naïve ideas (to whom the author contributed himself) is deliberately one-sided; by adding some black to the pearly-white idealism of citizen engagement, one might end up with a more appropriate grey. While less exciting, this allows for a more nuanced understanding of participation, and in the end, a more realistic approach that allows for actual change (Section 4).

\section{Limitations of Citizen Engagement as a Concept: Failures of the Light Side}

The current situation did not come without warning signs. Earlier research revealed a reluctance among professionals to give up control in the production process and a rather limited willingness of audience members to participate for free in this process (Singer et al. 2011). Instead of the ambitious full participation in the news-making process, many companies simply set up "walled gardens" for limited participation in comment sections (Domingo et al., 2008; Hanitzsch \& Quandt, 2012). The more active prod/users (Bruns, 2008) often chose to completely bypass journalism (Pavlik, 2000) and disseminate their idea of news via social networks and other online services (one prominent current example is a notoriously Twittering president), thereby questioning the monopoly and the very idea of professionalized news production by journalistic institutions. In many ways, entrepreneurial journalism-sometimes a precarious existence under de-institutionalized work conditions-echoes the impact of this cultural change (Cohen, 2015). So the empirical reality of user participation was a different one from the expectations for years now-and arguably, even from the beginning.

However, the problem cannot be simply attributed to a brilliant concept gone astray, as if a wonderful machinery just corroded into a deplorable state of malfunctioning. Rather, the whole proposition of grassroots journalism was one-sided from the beginning; it was a democratic and economic utopia that primarily revolved around the journalistic perspective and academic wishful thinking (Peters \& Witschge, 2014). Löffelholz (2004) noted early on that the broad notion of a "redactional society" (Hartley, 2000) had a weak empirical and theoretical foundation. In most of the forward-looking concepts, the "user" was indeed a projection-either an altruistic democrat in constant Samaritan mode or a particle in a willing workforce contributing to the journalist's own processes as a free resource. It may be argued that such projections primarily mirrored academic or economic Shangri-las that did not take the users as human beings seriously enough. As Gans (2003) noted, ideal democracies would have ideal citizens, but such ideals 
are meant to set societal goals, and therefore, remain intentionally simplistic. Actual (i.e., "real") societal life is much more complex (Gans, 2003), and most citizens are not motivated to fulfil the democratic ideal per se by gratuitously helping journalists inform their fellow citizens. It seems rather plausible that many would prefer to do something rather mundane instead (like relaxing after their daily paid work with a cool drink, watching television, meeting with friends etc.). ${ }^{1}$

However, such common-sense, down-to-earth thinking was not particularly popular in most of the early concepts of user participation in the news-making process; most of them were enthusiastically aiming for the sky. The reasons for this are multifaceted. Some major fallacies of the enthusiastic concepts of the late 1990s and early 2000 s were biased observations driven by selfinterest (idealistic or economic), projecting potentials and options as social reality, a rather weak consideration of the psychological and societal basis of human action, a lack of empirical work in concomitance with an abundance of conceptual work, and a disregard of the reasons for the institutionalization and professionalization of journalism.

As noted above, the idealistic bias on the part of academics was, in part, driven by their own interests and hopes regarding a democratic transformation and rejuvenation of journalism. This, perhaps naïve, approach may be also linked to the main protagonists at that time being primarily a younger generation of tech-savvy researchers. In contrast to many of their seniors, they had day-to-day experience with online communication, a more natural approach to computer technology (as they, themselves, were more or less digital natives), and based on their career stage, many were also eager to do things differently. Leaving behind the dusty environment of journalistic dinosaurs in traditional newsrooms and turning towards the dynamic, evolving new animals in the online world was certainly attractive. Also, their focus on the new came quite naturally with a preference for the exceptional over the normal. Their research was abundant in case-study examples of innovative best-practice examples of online news production and user participation and fewer with large-scale overviews of the overall state of the news media business. ${ }^{2}$

The media business' bias was certainly a different one. The fantasies of media managers were economic ones (Domingo et al., 2008; Vujnovic et al., 2010) that regarded the user as a cheap resource in the work process, basically producing content like "magic" out of nothing (Quandt, 2011). Naturally, there was an inherent cost- reduction idea involved here, that is, replacing paid journalists with voluntarily working users. Also, the walled gardens of comment sections were primarily meant as a means to promote customer loyalty, not as place for democratic debate that included both professional journalists and citizens (Singer et al., 2011). It is no wonder that the ideas of "user-generated content" and "participation" discussed in academia resonated well within parts of the industry (albeit for the wrong reasons). To put it more bluntly, while most academics meant "saving journalism" and "strengthening democracy", some media managers heard "saving money" and "strengthening our business".

In addition to this, there was also a certain lemminglike ${ }^{3}$ mentality in some media houses; as more and more news outlets introduced comment sections and participatory formats, it became fashionable to do this, and many just did it because everybody else did it. This bandwagon effect was quite pronounced; not to be left behind and having the appearance of being "modern" was often the primary motivation. This sometimes led to bizarre situations. As a researcher in the field, I was once contacted by an editor of a small publishing house to help them participate in participation. When being asked why they wanted to include user input in the first place, the editor answered (somewhat irritated): "Because the management wants it like that" (Quandt, 2012). I labeled this strategy "something 2.0" back then (Quandt, 2012)-a principle that probably could be transferred to "anything $x .0$ " even today.

The rather different goals notwithstanding, both approaches, by academia and the industry, were equally confusing technological options and economic potential with social reality. The differentiation between these (and the analysis of their complex interplay) is probably one of the most fundamental ideas of science and technology studies (STS), but their equalization remains a common mistake. The fallacy of confusing options with social realities is not just bound to technological innovations, though it runs deeper and is connected to a general perspective on human beings. Indeed, even in the early works of moral and political philosophy, it has been argued that there are reasons why societies come into existence and why people participate in larger, organized contexts. Centuries of this work led to the conclusion that participation does not automatically come free of charge, but is motivated by specific human interests and qualities and framed by the necessities of growing social structures. The darker view in the tradition of Hobbes' (1651/2008) Leviathan paints a self-

\footnotetext{
${ }^{1}$ This comment is not meant to downplay the considerable motivation of citizens to contribute to social causes, charity, welfare organizations etc.; however, there are significant differences of such activities to working for free for (mostly) profit-driven news organizations. One may also argue that such activities are much more "tangible" and the beneficial effects less abstract than "saving democracy through participation in journalism".

${ }^{2}$ An example of such case-oriented approaches can be found in the two edited books by Paterson and Domingo on online newsroom ethnographies (Paterson \& Domingo, 2008; Domingo \& Paterson, 2011). These two books were significant in developing the field of ethnographic research, so this is not at all meant as a criticism of their approach (full disclosure: I even contributed a study to Paterson \& Domingo, 2008). On the contrary; the argument here is rather a criticism of what is not there or at least lacking, that is, more critical work putting such approaches to innovation in journalism into perspective, thus balancing that period's work more.

${ }^{3}$ This expression is borrowed from a reviewer comment and was included here as it mirrors my own experiences with industry contacts during that time quite well.
} 
ish, interest-driven, and competitive picture of humans in their natural state with the societal rules and structures being borne out of "cold" reason and resulting in submission to authority. Rousseau's (1762/2018) Social Contract paints a much more positive image of the natural human state-peaceful, empathic, free, and noncompetitive-and acknowledges the realities of evolving societies, but it aims for an idealized democracy beyond the corruption of social realities. One could argue that many researchers (perhaps unknowingly) followed Rousseau's ideals in their concepts of participation, hoping that citizens would be intrinsically motivated, as if they were still in an idealized natural state. Interestingly enough, even the economic fantasies of media managers seemed to take participation as an intrinsic value for granted, which is somewhat ironic considering that economic thinking is often firmly rooted in a concept of humans as primarily competitive and selfish.

However, one does not have to follow the darker Hobbesian idea (or indeed, refer to moral philosophy at all) to realize that there is a difference between an idealized human condition and social reality. Various factors influence the news-production process, and the enthusiastic approach to online participation reduced this to the technological potential of users taking part in the process (Domingo et al., 2008) and somehow freeing them from the one-sided production of traditional journalism. However, that process is not just a result of technological necessity, but, on a structural level, of labor organization, and on a personal level, of motivation; so there are many reasons why not everybody can or should be a journalist.

Indeed, as noted above, the idea of user participation was neither acknowledging the value of professionalization enough (actually, it very much opposed it) nor did it consider the results of psychological research on motivation. The inner urge to participate in the public debate (Bowman \& Willis, 2003; Deuze, Bruns, \& Neuberger, 2007), that is, to provide commercially operating news media with free content, was taken for granted based on the assumption as a quasi-requirement for the citizen of modern society-aka "our democratic duty." 4 As a result, crucial questions did not receive enough attention: did many people show an urgent and obvious interest in news production? Why should users actually contribute something to professional news media, and what incentive would drive them to actually do this? Or, more bluntly put: why should anybody want to be a "citizen journalist"? The answers might have been quite different from the enthusiastic theoretical concepts. Actually, participation of a majority of the citizens simply for intrinsic reasons might have been highly unlikely, and external incentives were lacking or half-heartedly implemented (like a gamification of participation via rank sys- tems). The lack of interest in user motivations in the early 2000s may be partially explained by the fact that most of the researchers in that particular field had a background in journalism research or even practical journalism; in many cases, their focus was still on the journalists and news media organizations with user-generated content becoming a part of that context (i.e., a notable resource in the production process that was still very much intact) (Domingo et al., 2008). This is actually inherent in the term "citizen journalist"; that is, it was thought that the people would become lay journalists and therefore assimilate into the system. This stands in stark contrast to the work of media effects researchers some ten years later where information sharing via social media is primarily conceptualized as a form of "private" online behavior and not as a form of public "news production" (often not being much different from what was discussed a decade before, except that it is happening in a different context, i.e., social media vs. legacy news media).

The sometimes rather broad re-conceptualizations of journalism were not backed up by empirical proof in most cases. Actually, there was a certain lack of empirical research beyond individual case analyses, especially in the early years of the development. As mentioned above, the initial focus on case studies and "outstanding" best-practice examples pronounced the extreme, neglecting the (potentially boring, but more prevalent) normal. One may still argue that in the beginning of a development, a heightened interest in the avant-garde is crucial to understand change. However, if such a nucleus of change is not contrasted with the overall state of the field, one might misinterpret innovations and their relevance (as a standard of comparison is missing). Indeed, some larger studies in the subsequent years cast doubt on the acceptance of user participation in news media and the motivation of users to contribute anything beyond comments (Karlsson, Bergström, Clerwall, \& Fast, 2015; Nielsen, 2014; Singer et al., 2011). At least in some countries, the journalists themselves were very skeptical about the usefulness of user contributions and their participation in online forums. Some were even doubtful of the citizens' principal potential to produce meaningful content (Singer et al., 2011).

On the one hand, one may perceive this as protectionism and a defensive reaction to the new competition with low- or non-paid workers. On the other hand, there are reasons for the existence of institutionalized journalism and why a profession usually is not only paid for, but also requires some form of qualification and skill. While the access to journalism does not depend on a formal qualification in many countries, there is vocational training on the job or even academic training available that teaches and reflects the rules and skillsets developed over the centuries as part of the profession. The

\footnotetext{
${ }^{4}$ The more recent concept of "reciprocal journalism" by Lewis, Holton and Coddington (2014) gives some alternative answers on a conceptual level. Again, the perspective here is structural rather than individual or motivational, but it acknowledges the benefit for users and followers and therefore does not reduce the analysis to a one-sided perspective on the (professional) production side. As Lewis (2015) pointed out, reciprocity can be also negative and anti-social-an argument that resonates well with the ideas discussed here.
} 
idea that journalism only requires specific personal qualifications was rejected by research long ago (Weaver \& Gray, 1980), so it's hardly surprising that untrained laymen (citizen journalists) may not contribute polished material that is ready for publication even if they are motivated to do so. This lack of ability, not simply motivation, was part of the discussion about participation early on (Singer et al., 2011). Some media just expected citizens to participate in the form of delivering raw material such as information on events, photos, eye-witness accounts, and feedback. In addition to individual qualifications necessary to do the job, professionalization also means institutionalization. The process of news production typically requires various skills, so the division of work plus a corresponding specialization is a natural result of growing news businesses; it's no wonder research revealed that in online journalism, specific work routines and production roles were quickly established on the basis of necessities and the logic of efficient work practices (Quandt, 2005). Similar processes were happening in blog-based, independent news outlets. Often these started as oneor few-person businesses, but with growth and success, they reinvented typical work routines of more traditional media houses and implemented horizontal and vertical differentiation.

In short, the enthusiastic concepts of citizen participation in the news-making process were partially shortsighted and ignored some framework conditions of professional, journalistic production processes, sometimes by virtue of idealism and sometimes due to an underestimation of the complex interplay of individual, structural, and social processes. However, hindsight is easier than foresight: The criticism here is based on retrospect, which always has the benefit of knowing the results, as well as the process that led to it. And while the concept of intrinsically motivated citizen participation might have been naïve, it was certainly important to initiate a discussion about the potential of innovative forms of news production and the importance of re-connecting journalism with the public. The subsequent debates on journalistic responsibility and community orientation were important to reveal issues of déformation professionelle and journalistic arrogance and can be regarded as part of a healthy re-calibration process.

There is a next step in this debate, though, and it somewhat turns the previous argument and perspective completely upside down. Lately, there is empirical and theoretical insight that points to quite successful forms of participation (at least from the perspective of the participants). However, these are not motivated by a belief in the democratic necessity of journalistic news production or an idealized citizen. On the contrary, they are often rooted in rather sinister motives and anti-democratic worldviews of the participating actors. In contrast to what was described above, these actors are often highly motivated and organized, so they actually have clear reasons to engage in "information" and "news" production.

\section{Dark Participation: Concept and Systematization}

The bleak flip side to the utopian concept of selfless participation in a redactional society (Hartley, 2000) as outlined above, could be called "dark participation". As research has revealed, this type of participation seems to be growing parallel to the recent wave of populism in Western democracies (Jouët, 2018; Manucci \& Weber, 2017; Meltzer, 2014). Instead of positive, or at least neutral, contributions to the news-making processes, it is characterized by negative, selfish or even deeply sinister contributions such as "trolling" (Coles \& West, 2016; Mihaylov \& Nakov, 2016), strategic "piggy-backing" on journalistic reputation, and large-scale disinformation in uncontrolled news environments (Aro, 2016; Coe et al., 2014; Muddiman \& Stroud, 2017). But why is that so? In parallel to the question regarding the "enthusiastic" participation model, one might ask more specifically: why does a non-professional actor with malevolent motives want to participate in the news-making process? And who are these alleged "citizens"?

In the following, I will sketch some initial cases that may hint at plausible answers before systematizing the concept of dark participation further. The examples that could be labelled dark participation range from misinformation and hate campaigns to individual trolling and cyberbullying. Many of these have been subject to recent public debate.

In 2014, The Guardian publicly announced that they found a high number of strategically placed, manipulative user posts in their comment sections. Throughout the Ukrainian crisis, the level of pro-Russian posts seemed to be disproportional, and there was evidence that linked these posts to the Russian government, or at least their support groups (Elliott, 2014). The work of pro-Russian "web brigades" or "troll armies" was observed early on (Franke \& Pallin, 2012; Kelly et al., 2012; Sanovich, 2017; Shakarian, 2011), and the actions of the St. Petersburg based Internet Research Agencybasically an organized troll farm-received broad attention after being exposed by Western journalists (Walker, 2015). The aim of these "participators" was to influence the Western public and (potentially) the journalists, according to the Russian state goals, in other words, basically a form of covert political propaganda. However, the Internet Research Agency is certainly not the only notable case; the list of similar examples is long (Erjavec \& Kovačič, 2012; Zelenkauskaite \& Balduccini, 2017) as is the list of presumed actors and groups (Weedon, Nuland, \& Stamos, 2017), ranging from state propagandists and political extremists to religious groups and conspiracy theorists all over the globe (see also Quandt \& Festl, 2017). Misinformation and propaganda can also take the form of hate campaigns that attack specific groups or individuals that symbolize these groups (Quandt \& Festl, 2017).

There are also many cases where misinformation has been spread via social networks and short messaging 
services (especially Twitter) either as "fake news" that was published under the name of news media (Allcott \& Gentzkow, 2017; Murtha, 2016) or as information intended to be picked up by media as genuine eye-witness reports or user opinions (Ellis, 2017; Gowen \& Bearak, 2017). Sneaking fake information into journalism by imitating trusted or innocent sources is a well-known propaganda strategy (Jowett \& O'Donnell, 2012) and can be seen as a particularly sinister form of dark participation. The originators plant false or misleading information and abuse the public's trust in journalistic brands. In addition to the potential impact when successfully manipulating journalists and getting their message into the news, the originators also cover their tracks and become invisible to outside observers.

Beyond these forms of obviously strategic, manipulative participation, there are also some reports of genuine trolling and bullying via comment sections. The motivations of forum trolls (Cheng, Bernstein, DanescuNiculescu-Mizil, \& Leskovec, 2017) have not received much attention in journalism research, but there are some revealing reports on individual cases (as an example, see Steppat, 2014). These paint the picture of angry, malevolent participants who project their personal issues and a general hatred for fellow human beings or "the system" onto others with a grim will to stir up forum debates. Also, trolling seems to be sometimes motivated by the simple enjoyment of causing turmoil and seeing others react to aggressive or nonsensical posts (Buckels, Trapnell, \& Paulhus, 2014). In addition to this, forums are sometimes the scene of targeted bullying. In contrast to trolling, cyberbullying is "intended to harass an 'inferior' victim"; it is "an intentional and deliberate act" that happens "more than once" and is directed "against a physically or socially inferior victim" (Festl \& Quandt, 2017, p. 329; see also Smith, Mahdavi, Carvalho, Fisher, \& Russell, 2008; Tokunaga, 2010). Unsurprisingly, there are no clear boundaries between trolling and cyberbullying. However, while trolls sometimes attack other forum members in their "arguments", their actions do not repeatedly target one specific individual in order to harass that person; their primary goal is to cause trouble. Both of these types of dark participation can be differentiated from the above mentioned strategic forms of cyber hate, which are:

Typically embedded in the actions of larger, more enduring hate movements or hate campaigns...and...targeted at whole groups defined by criteria such as race, ethnicity, gender, religion, and so on-and (mostly) not at single victims or at singular events. (Quandt \& Festl, 2017, p. 336)

In contrast to trolling and bullying, strategic manipulation "serves an ideological, political, or religious goal" (Quandt \& Festl, 2017, p. 338), so if individuals are attacked, they typically "stand for" a target group or an opposing principle (i.e., they signify "the enemy").
These examples point to the comment sections as a central target of dark participation. There are reasons for this; the comment sections are a good object of manipulation and hate because they basically offer an already established, large audience "for free" for strategic agitators and trolls. The environment also has the blessing of an established news source; that is, dark participators benefit from the media brand and the environment it offers. Also, due to the closure of the journalistic process to very limited walled gardens of user debate, the comment sections are often the only directly accessible step of the production chain (Singer et al., 2011). Some indirect influence can also be exerted by feeding tampered material to online media under the disguise of ordinary citizens or eye witnesses (as noted above), but depending on the level of fact checking, this might be a more difficult route.

Similar to the comment sections, malevolent participators might invade social media channels providing news items. Shared content on Facebook, Twitter, YouTube, etc. is subject to comparable "dark" commenting strategies, and in many ways, the situation is worse there because the news originators cannot exert the same level of control as in their own proprietary comment sections. Additionally, social media channels often give access to all levels of the production chain (as described in Singer et al., 2011) offering the option to publish news pieces without the involvement of professional journalists, therefore fully bypassing legacy media, or to release fake news or manipulated news pieces under the name of professional journalists and established media (Quandt, Frischlich, Boberg, \& Schatto-Eckrodt, in press).

Through the above examples (misinformation, hate campaigns, trolling, cyberbullying), the shape and focal areas of dark participation become roughly visible. However, it is important to explore the concept beyond the idiosyncrasies of the individual case examples in order to not fall into the same trap as the primarily case driven "enthusiastic" research on participation. Therefore, in the following, I would like to dissect the variants of dark participation in more detail by differentiating several main dimensions: (a) wicked actors, (b) sinister motives and reasons for participation, (c) despicable objects/targets, (d) intended audience(s), and (e) nefarious processes/actions (Figure 1). Such a systematic approach provides an understanding of the huge variety and differences in various phenomena that fall into the category of dark participation. While exploring these dimensions, I will also briefly discuss some of the knowledge we already have on them (albeit some of the findings are, indeed, still limited).

\subsection{Actors}

As indicated by the above case examples, actors of dark participation vary from individuals and organized groups to synchronized movements (and corresponding larger groups). Individual actors may be single trolls or hate 


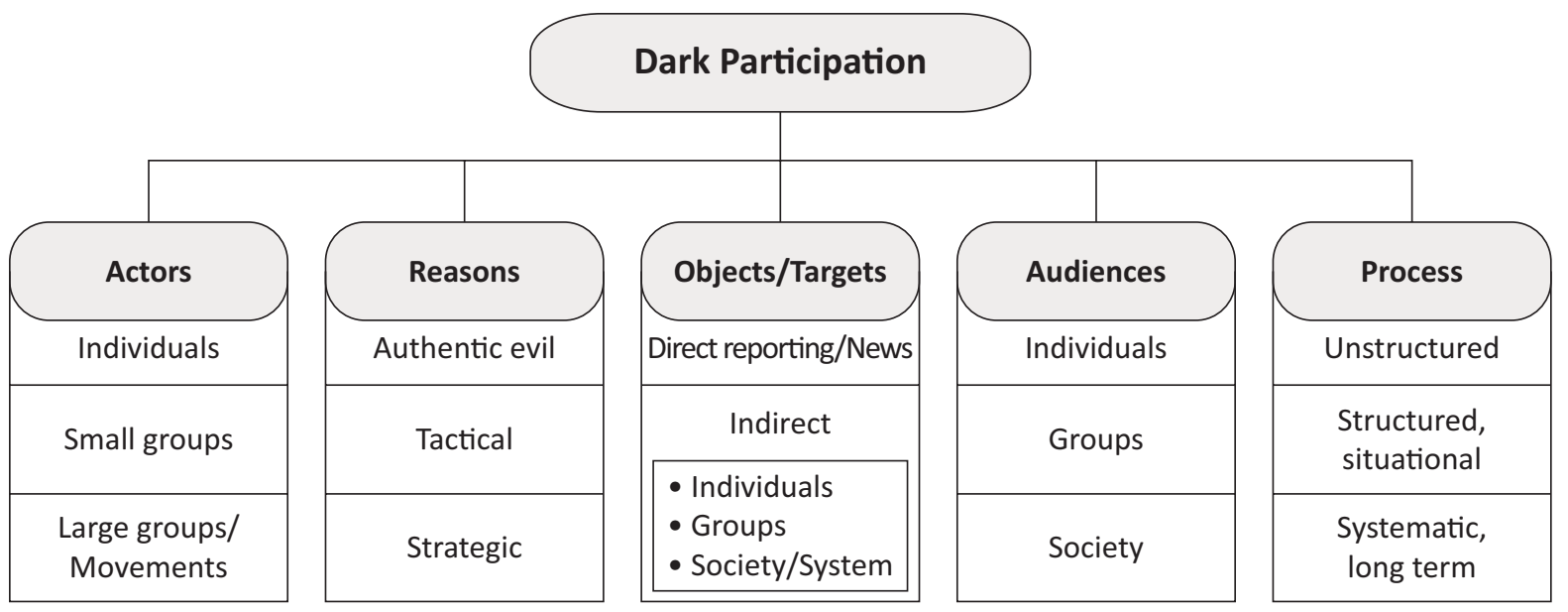

Figure 1. Variants of dark participation.

mongers with varying backgrounds, motivations, and participation behaviors that may be idiosyncratic (as they are rooted in the respective person's biography and circumstance). Still, there are specific types of individual trolls; some are obviously using hate postings to compensate for personal discontent (Steppat, 2014), while others appear to find it satisfying to stir up trouble or manipulate others (Buckels et al., 2014). The typical Internet troll is thought to be a single "lone wolf" (Steppat, 2014), but especially, "fun trolling" might not be as misanthropic as "hate trolling", and therefore, it is also open to group behavior. Such small groups of actors are also not uncommon as perpetrators in cyberbullying. A cooperation principle, including active bullies and supportive audience members (Festl \& Quandt, 2017), is inherent to many bullying constellations with the perpetrator group being united by the joint action against specific targets. Joint action in various forms of dark participation also extends to larger groups that can be described as part of a political, religious, or ideological movement. Manipulative forms of participation in online forums are often strategically planned and synchronized. The above-mentioned actions of Russian propaganda brigades, but also of various other covert state agencies, right-wing populists, or conspiracy theorists are usually not simple coincidence (Gorwa, 2017; King, Pan, \& Roberts, 2017; Pingaud \& Sauer, 2016). They follow a specific sequence and logic, apply well-calculated messages that serve a specific goal, and are not as unpredictable as individual trolls.

\subsection{Reasons and Motives}

The motives and reasons for dark participation vary notably with the actor groups. Individuals are plausibly more prone to something that might be labeled "authentic" evil attacks; that is, their actions are morally bad and driven by genuine personal hate for others or the sheer pleasure of making others suffer (Craker \& March, 2016; Erjavec \& Kovačič, 2012). In contrast to a planned group action, such attacks do not follow a rational logic, and from the outside, they may appear random, affective, and/or psychotic. Other forms of dark participation are much more controlled or planned; the reasons may still be situational or short term in some cases, but they are following specific tactics (as is the case with some instances of bullying) (Festl \& Quandt, 2017). Large scale manipulation campaigns are strategic by definition, and while such forms are often particularly sinister, they still apply a rational (cold) logic and process (Quandt \& Festl, 2017). Organized hate speech in online forums applies demeaning language intentionally, and hate in this context is not to be confused with situational rage (although it seems to be emotionally loaded, which is part of a strategy to appeal to specific target groups).

\subsection{Objects and Targets}

The objects and targets of both mis/disinformation and negative/covert comments have to be discerned from the intended audience(s) of dark participation. Depending on the motives of wicked actors, the objects can be normal topics of reporting or hand-picked targets (like political or societal representatives that are exemplary for a despicable group or principle). Trolls and manipulators may attack specific articles or topics, and they can also divert content-driven hate to actors mentioned in the article or the journalists themselves. A typical example of this is the behavior of right-wing commenters who target articles on refugees (Devlin \& Grant, 2017; Toepfl \& Piwoni, 2017), and depending on the article's tone, also attack the journalists as being responsible for the content and its tone. In Germany, this basic principle was generalized in the form of the Lügenpresse (press of liars) accusation, especially advanced by the right-wing, anti-Islam and anti-refugee movement, PEGIDA (see also Quandt et al., in press). Here, the press and journalism in general became representative of an adverse system and the intended target of the negativity. 


\subsection{Audiences}

The intended audience is often different from targeted persons or groups, and again, can range from individuals to groups to whole societies (see also Quandt \& Festl, 2017). A typical example is forum participation by strategic actors. They first criticize an article (let's say, in the case of the Russian web brigades, a piece on Putin published in a German web magazine), transfer the criticism to the journalist as originator (claiming that her/his reporting was biased), and then escalate this to a systemic level (insinuating that this is typical for biased reporting on Russia in Germany). ${ }^{5}$ So the direct, initial target is the article itself, but then it is diverted to indirect targets (journalists, the media, the system). However, the intended audience of such posts may be different from the targets. It could be the other forum participants, as part of the respective population and potential multiplicators, but also the journalists themselves (by giving them the impression that their reporting is not in line with their audience's perceptions and wishes) or maybe even third parties (who might hear about the user reactions from media reports). The effects of such forms of dark participation may be slow and indirect, following the "constant dripping wears away a stone" principle (Stelzenmüller, 2017), but they may affect whole societies as the intended audience. Here, one goal is potentially changing the reference system of what can and should be said in a society, and the framing of these discussions (i.e., in the long term, a societal norm shift).

\subsection{Process}

From the previous points, it is apparent that there are varying strategies when it comes to the processes of dark participation, from single, limited events to longterm strategies of subversion, in line with the underlying motives of the actors, the targeted objects, and the intended audiences. Individual hate trolling as an unpredictable series of psychotic outbreaks may be unstructured and random, whereas tactically motivated interventions are typically structured, but still bound by the specifics of the situation. Strategic forms of dark participation, on the other hand, are systematic and long-term processes. Feeding journalists tampered information or influencing forum participations according to one's own ideology may require advance planning, careful execution, and repetition to achieve the strategic goals (Marwick \& Lewis, 2017).

This very brief differentiation of the most relevant dimensions and variants of dark participation hints at a large variety of phenomena that may be grouped under that label. Obviously, there are cognate concepts, like disinfor- mation, propaganda, and populism (Jowett \& O'Donnell, 2012) or fake news (Rubin, Chen, \& Conroy, 2015), but these are linked to different academic debates and perspectives. In this article, I deliberately focused the phenomena through the lens of participation, that is, "taking part in something else" such as the news production process, and I did so to contrast the dark side with the enthusiastic debate. It should have become apparent by now that the potential for dark participation is enormous and that there is also empirical proof that it may be quite successful, with intrinsically motivated actors eager to participate and contribute (but just not in the way journalism researchers dreamt of).

In contrast to the enthusiastic concepts of participation, the question, "why would anyone want to participate?" is much easier to answer for dark participation. The former was (at least implicitly) relying on the average user as an idealized democratic citizen who is willing to contribute for a higher good and out of an intrinsic motivation-an assumption that has obvious flaws under real life conditions. The latter does not rely on an idealistic general audience as participators, but is driven by very particular, often selfish interests of specific individuals and groups. The dark participators have extreme ideas and messages, and they try to get these out into the public with missionary zeal and by any means necessary. So while the enthusiastic concept of participation expected exceptional motivation from the normal audience, dark participation merely assumes motivated exceptions from the norm. As such a requirement for the concept is easily met, the future for dark participation is, paradoxically, bright.

\section{Beyond Doom and Gloom: Save Journalism, Save the World?}

Hateful comments, manipulation of forums, and fabricated information seem to be common features of user participation in the news-making process these days. These and other variants of dark participation are apparently on the rise. While journalism researchers in the 1990s and 2000s enthusiastically hoped for a rejuvenation of journalism and a strengthening of democracy by means of citizen participation in a positive and civil debate, anecdotal evidence and empirical research have pointed in exactly the opposite direction recently (Gardiner et al., 2016; Karlsson et al., 2015; Rowe, 2015; Su et al., 2018). As a result, some media limit their options of participation to the walled gardens of user comments, filter and moderate user posts, or install fact-checking units to double and triple analyze user-generated content for authenticity (Newman, 2017; Santana, 2016; Wolfgang, 2018)-a seemingly desperate attempt at putting the genie back into the bottle. Indeed, the situation seems

\footnotetext{
${ }^{5}$ This example is not a hypothetical one; it was communicated to a research team on web-based propaganda where I serve as one of the PIs (http://www.propstop.de/?lang=en), actually by several directly affected journalists. So it seems to be a common observation, and not just an individual case. However, the journalists reported many more comparable cases, by various actors, and not just the Russian web brigades; one has to be careful to not attribute this to a single group or nation.
} 
to be grim, and many observers these days note that the Internet has become an unfriendly and hostile place (Rainie, Anderson, \& Albright, 2017) that is full of hate and fake news (Lazer et al., 2018; Seely, 2018); positive participation sometimes looks like lost cause.

Given my ruthless criticism of early participation research at the beginning of this article, you might think that this assessment actually suits me as the author of a personal vendetta piece. Indeed, this article has been, in part, a very personal reckoning with earlier work on participation. I myself contributed to the enthusiastic debate on "saving journalism" through citizen participation and new online concepts. As noted, this idealistic perspective was well intended, but partially misguided and naïve. By introducing the concept of dark participation, I tried to show that there is a large variety of participation behaviors that are evil, malevolent, and destructive-at least if one believes in the value of democracy and free, impartial information flow. The examples and systematization paralleled previous analyses of positive options, but completely flipped them around (Domingo et al., 2008; Quandt, 2011; Singer et al., 2011). This was an intentional deconstruction.

If you now believe that the future is all doom and gloom, then you have stepped into a trap I intentionally set.

The examples of dark participation point to urgent issues of current online communication and news processes, and there is sufficient proof that these issues are more than serious. Without any doubt, it is highly necessary to research them. However, the current wave of apocalyptic analyses of media and society are partially born out of the same fallacies that plagued the early enthusiastic approaches. Again, researchers want to "save something important, a societal institution that seems to be falling apart both economically and democratically" (as noted in the very beginning of this piece); the difference now is that they are focusing on the many diabolic problems and not a messianic solution (which are, ironically, the two sides of the very same coin-participation). Science has fads that come in waves, and with the disappointment regarding earlier concepts and hopes, researchers again feel that these earlier ideas were stuck in crystallized traditions. Positive forms of participation now seem awfully outdated, and the many threats of online communication are the latest and, seemingly, the most important trend.

The issue here is not the (most relevant) topic of dark participation itself, but a growing lopsidedness that repeats the earlier failings in approach, just with an inversed object of interest. One has to wonder, if there are, again, "biased observations driven by self-interests, projecting potentials and options as social reality, a rather weak consideration of the psychological and societal basis of human action, a lack of empirical work in concomitance with an abundance of conceptual work, and a disre- gard of the reasons for the institutionalization and professionalization of journalism" (to quote the ruthless reckoning in Section 2)?

Indeed, when looking at certain current obsessions with fake news, populism, and hate, one may be inclined to answer at least some of these questions with a "yes" maybe a conditional one, but still a "yes." Some of the current wave of research on hate speech in user comments, Twitter manipulation, or online propaganda consistently fails to offer a benchmark on how relevant these cases are in relation to the overall information flow. By pointing out that thousands or even millions of tweets are without a factual basis, they do not prove much beyond common knowledge; and with extremely low usage numbers in some countries, even millions of tweets are basically read by negligible fragments of the public. Similarly, research on the impact of bots and fake profiles often projects the potentials and options as social reality. Many of the studies in the field primarily offer casestudy examples, and even concrete numbers on the percentage of social bots and fake profiles in specific comment sections or social media channels do not give a scale for their actual effect on society. Once again, media and communication research must be careful that it is not taking the exception as the rule.

I hope that you do not take this the wrong way. These types of research are important, even essential, as are other analyses of dark participation ${ }^{6}$, and they help us in understanding societal changes under the conditions of an increasingly "total" media logic. However, as researchers, we should be careful to not make the exact same mistakes over and over again. To basically follow the earlier path of research, but in a reversed logic, would mean throwing the baby out with the bathwater.

Journalism and the world as we know it are not saved by academic enthusiasm alone; neither are they destroyed by scientific (and public) doom and gloom. What the discussion on participatory journalism - and indeed, the role of news in a technologically and socially changed world-needs is more balance. A normalization of the debate and maturity beyond uni-polar depictions of the world is essential. As such, the concept of dark participation introduced here was, indeed, part of a trick argument. At first, it just reveals that there is a bleak flipside to the enthusiastic concept of participation, but it is certainly not meant to simply replace it or to replicate the basic principle just by coloring it black. Indeed, the recent public and academic outcry against a decline of culture (Anderson, Yeo, Brossard, Scheufele, \& Xenos, 2018; Burkeman, 2017) is potentially as misguided as the naïve enthusiastic embrace of citizen participation was.

I would argue that a future agenda for the research on participation must accept and include both perspectives, light and dark, and it needs to offer clearer benchmarks on the societal relevance of both phenomena and everything in between. Forms of participation, either

\footnotetext{
${ }^{6}$ And indeed, I have to fully disclose that I also contributed to this discussion with more recent research on propaganda and populism, also in user comments and participatory formats, and its impact on journalism. Another mea culpa may be necessary at a later point of time.
} 
helpful or destructive, should not only be studied as detached cases, extreme exceptions, or mere potential but also as notable factors in the crucial information flow of societies. This would require the development of integrative theories on the conditions of participation that are neither driven by wishful thinking nor doom and gloom. Therefore, what we need in the debate is another stage of development beyond simple black and white-a more realistic and healthy debate that reflects human and social life in all its glorious shades of grey.

\section{Acknowledgments}

I would like to thank both reviewers and the thematic issue editors for their valuable input and alternative perspective, which helped hone this essay's argument. Furthermore, I would like to thank Niels Göran Mede for his help in acquiring relevant literature and double-checking references.

\section{Conflict of Interests}

The author declares no conflicts of interest.

\section{References}

Allan, S. (2006). Online news: Journalism and the internet. Maidenhead: Open University Press.

Allcott, H., \& Gentzkow, M. (2017). Social media and fake news in the 2016 election. Journal of Economic Perspectives, 31(2), 211-236.

Anderson, A. A., Yeo, S. K., Brossard, D., Scheufele, D. A., \& Xenos, M. A. (2018). Toxic talk: How online incivility can undermine perceptions of media. International Journal of Public Opinion Research, 30(1), 156-168.

Aro, J. (2016). The cyberspace war: Propaganda and trolling as warfare tools. European View, 15(1), 121-132.

Bivens, R. K. (2008). The Internet, mobile phones and blogging: How new media are transforming traditional journalism. Journalism Practice, 2(1), 113-129.

Bowman, S., \& Willis, C. (2003). We media: How audiences are shaping the future of news and information. Reston, VA: The Media Center at the American Press Institute. Retrieved from http://www.hypergene. net/wemedia/download/we_media.pdf

Bruns, A. (2008). Blogs, Wikipedia, Second Life and beyond: From production to produsage. Pieterlen: Peter Lang.

Buckels, E. E., Trapnell, P. D., \& Paulhus, D. L. (2014). Trolls just want to have fun. Personality and Individual Differences, 67, 97-102.

Burkeman, O. (2017, November 30). The vortex: Why we are all to blame for the nightmare of online debate. The Guardian. Retrieved from https://www. theguardian.com/media/2017/nov/29/vortex-online -political-debate-arguments-trump-brexit

Cheng, J., Bernstein, M., Danescu-Niculescu-Mizil, C.,
\& Leskovec, J. (2017). Anyone can become a troll: Causes of trolling behavior in online discussions. Paper presented at The Conference on ComputerSupported Cooperative Work, Portland, OR.

Coe, K., Kenski, K., \& Rains, S. A. (2014). Online and uncivil? Patterns and determinants of incivility in newspaper website comments. Journal of Communication, 64(4), 658-679.

Cohen, N. S. (2015). Entrepreneurial journalism and the precarious state of media work. South Atlantic Quarterly, 114(3), 513-533.

Coles, B. A., \& West, M. (2016). Weaving the internet together: Imagined communities in newspaper comment threads. Computers in Human Behavior, 60, 44-53.

Craker, N., \& March, E. (2016). The dark side of Facebook $^{\circledR}$ : The Dark Tetrad, negative social potency, and trolling behaviours. Personality and Individual Differences, 102, 79-84.

Deggerich, M. (2001a, June 21). Gute Seiten, schlechte Zeiten [Good sites, bad times]. Die Zeit. Retrieved from http://www.zeit.de/2001/26/200126_ c-medien-online.xml

Deggerich, M. (2001b). Igittigitt! [Yuck!] Medium Magazin, 1, 60-61.

Deuze, M. (2003). The web and its journalisms: Considering the consequences of different types of news media online. New Media \& Society, 5(2), 203-230.

Deuze, M., Bruns, A., \& Neuberger, C. (2007). Preparing for an age of participatory news. Journalism Practice, 1(3), 322-338.

Devlin, A. M., \& Grant, C. (2017). The sexually frustrated, the dumb and the libtard traitors: A typology of insults used in the positioning of multiple others in Irish online discourse relating to refugees, asylum seekers, immigrants and migrants. European Journal of Communication, 32(6), 598-613.

Domingo, D., \& Paterson, C. (2011). Making online news. Volume 2: Newsroom ethnographies in the second decade of Internet journalism. Pieterlen: Peter Lang.

Domingo, D., Quandt, T., Heinonen, A., Paulussen, S., Singer, J., \& Vujnovic, M. (2008). Participatory journalism practices in the media and beyond: An international comparative study of initiatives in online newspapers. Journalism Practice, 2(3), 326-342.

Elliott, C. (2014, May 4). The readers' editor on...proRussia trolling below the line on Ukraine stories. The Guardian. Retrieved from https://www.theguardian. com/commentisfree/2014/may/04/pro-russia-trollsukraine-guardian-online

Ellis, G. E. (2017, April 30). Inside the conspiracy theory that turned Syria's first responders into terrorists. Wired. Retrieved from https://www.wired.com/ 2017/04/white-helmets-conspiracy-theory

Erjavec, K., \& Kovačič, M. P. (2012). "You don't understand, this is a new war!" Analysis of hate speech in news web sites' comments. Mass Communication and Society, 15(6), 899-920. 
Esau, K., Friess, D., \& Eilders, C. (2017). Design matters! An empirical analysis of online deliberation on different news platforms. Policy \& Internet, 9(3), 321-342.

Festl, R., \& Quandt, T. (2017). Cyberbullying. In P. Rössler (Ed.), The international encyclopedia of media effects (pp. 328-336). Malden: Wiley-Blackwell.

Franke, U., \& Pallin, C. V. (2012, December). Russian politics and the Internet in 2012 (FOI Report No. FOI-R3590-SE). Stockholm, Sweden: Swedish Ministry of Defence. Retrieved from https://www.foi.se/reportsearch/pdf?fileName=D\%3A\%5CReportSearch\%5CFi les\%5Cebb043f5-26fc-41be-982bda589398eeb7.pdf

Gans, H. (2003). Democracy and the news. Oxford: Oxford University Press.

Gardiner, B., Mansfield, M., Anderson, I., Holder, J., Louter, D., \& Ulmanu, M. (2016, April 12). The web we want: The dark side of Guardian comments. The Guardian. Retrieved from https://www.theguardian. com/technology/2016/apr/12/the-dark-side-of-guard ian-comments

Gorwa, R. (2017). Computational propaganda in Poland: False amplifiers and the digital public sphere (Working Paper 2017.2). Oxford: Project on Computational Propaganda.

Gowen, A., \& Bearak, M. (2017, December 8). Fake news on Facebook fans the flames of hate against the Rohingya in Burma. The Washington Post. Retrieved from https://www.washingtonpost.com/2c1fe830ca1f-11e7-b506-8a10ed11ecf5_story.html

Hanitzsch, T., \& Quandt, T. (2012). Online journalism in Germany. In E. Siapera \& A. Veglis (Eds.), The handbook of global online journalism (pp. 429-444). Oxford: Wiley-Blackwell.

Harlow, S. (2015). Story-chatterers stirring up hate: Racist discourse in reader comments on US newspaper websites. Howard Journal of Communications, 26(1), 21-42.

Hartley, J. (2000). Communicative democracy in a redactional society: The future of journalism studies. Journalism, 1(1), 39-48.

Hermida, A. (2010). Twittering the news: The emergence of ambient journalism. Journalism Practice, 4(3), 297-308.

Hille, S., \& Bakker, P. (2013). I like news. Searching for the "Holy Grail" of social media: The use of Facebook by Dutch news media and their audiences. European Journal of Communication, 28(6), 663-680.

Hobbes, T. (2008). Leviathan. Oxford: Oxford University Press. (Original work published 1651)

Jouët, J. (2018). Revisiting digital news audiences with a political magnifying glass. Javnost-The Public, 170(29), 1-8.

Jowett, G. S., \& O’Donnell, V. (2012). Propaganda and persuasion (5th ed.). Los Angeles, CA: Sage.

Karlsson, M., Bergström, A., Clerwall, C., \& Fast, K. (2015). Participatory journalism-The (r)evolution that wasn't: Content and user behavior in Sweden
2007-2013. Journal of Computer-Mediated Communication, 20(3), 295-311.

Kelly, J., Barash, V., Alexanyan, K., Etling, B., Faris, R., Gasser, U., \& Palfrey, J. (2012). Mapping Russian Twitter (Berkman Center Research Publication No. 20123). Cambridge, USA: The Berkman Center for Internet \& Society at Harvard University. Retrieved from https://cyber.harvard.edu/sites/cyber.law.harvard. edu/files/Mapping_Russian_Twitter_2012.pdf

King, G., Pan, J., \& Roberts, M. E. (2017). How the Chinese government fabricates social media posts for strategic distraction, not engaged argument. American Political Science Review, 111(3), 484-501.

Lazer, D. M. J., Baum, M. A., Benkler, Y., Berinsky, A. J., Greenhill, K. M., Menczer, F., . . . Zittrain, J. L. (2018). The science of fake news. Science, 359(6380), 1094-1096.

Lewis, S. C. (2015). Reciprocity as a key concept for social media and society. Social Media + Society, 1(2), 1-2.

Lewis, S. C., Holton, A. E., \& Coddington, M. (2014). Reciprocal journalism. A concept of mutual exchange between journalists and audience. Journalism and Mass Communication, 8, 229-241.

Löffelholz, M. (2004). Einführung in die Journalismustheorie: Theorien des Journalismus. Eine historische, metatheoretische und synoptische Einführung [Introduction to journalism theory: Theories of journalism. A historic, meta-theoretical and synoptic introduction]. In M. Löffelholz (Ed.), Theorien des Journalismus. Ein diskursives Handbuch [Theories of journalism. A discursive handbook] (2nd ed., pp. 17-63). Wiesbaden: VS Verlag für Sozialwissenschaften.

Manucci, L., \& Weber, E. (2017). Why the big picture matters: Political and media populism in Western Europe since the 1970s. Swiss Political Science Review, 23(4), 313-334.

Marwick, A. \& Lewis, R. (2017, May 15). Media manipulation and disinformation online. New York, NY: Data \& Society Research Institute. Retrieved from http://www.chinhnghia.com/DataAndSociety_Media ManipulationAndDisinformationOnline.pdf

Meltzer, K. (2014). Journalistic concern about uncivil political talk in digital news media. The International Journal of Press/Politics, 20(1), 85-107.

Mihaylov, T., \& Nakov, P. (2016). Hunting for troll comments in news community forums. In Proceedings of the 54th annual meeting of the Association for Computational Linguistics (pp. 399-405). Berlin: Association for Computational Linguistics.

Muddiman, A., \& Stroud, N. J. (2017). News values, cognitive biases, and partisan incivility in comment sections. Journal of Communication, 67(4), 586-609.

Murtha, J. (2016, May 26). How fake news sites frequently trick big-time journalists. Columbia Journalism Review. Retrieved from https://www.cjr. org/analysis/how_fake_news_sites_frequently_trick _big-time_journalists.php

Neurauter-Kessels, M. (2013). Impoliteness in cy- 
berspace. Personally abusive reader responses in online news media (Unpublished Doctoral Dissertation). University of Zürich, Zürich, Switzerland. Retrieved from https://opac.nebis.ch/ediss/20131752.pdf

Newman, N. (2017). Journalism, media and technology trends and predictions 2017. Oxford: The Reuters Institute for the Study of Journalism. Retrieved from https://reutersinstitute.politics.ox.ac. uk/our-research/journalism-media-and-technologytrends-and-predictions-2017

Nielsen, C. E. (2014). Coproduction or cohabitation: Are anonymous online comments on newspaper websites shaping news content? New Media \& Society, 16(3), 470-487.

Paterson, C., \& Domingo, D. (2008). Making online news: The ethnography of news media production. Pieterlen: Peter Lang.

Pavlik, J. (2000). The impact of technology on journalism. Journalism Studies, 1(2), 229-237.

Pavlik, J. (2001). Journalism and new media. New York, NY: Columbia University Press.

Peters, C., \& Witschge, T. (2014). From grand narratives of democracy to small expectations of participation. Journalism Practice, 9(1), 19-34.

Pingaud, E., \& Sauer, B. (2016). Framing differences: Theorising new populist communicative strategies on the Internet. In M. Ranieri (Ed.), Routledge research in education. Populism, media and education. Challenging discrimination in contemporary digital societies ( $\mathrm{pp}$. 26-43). London, UK: Routledge.

Quandt, T. (2005). Journalisten im Netz: Eine Untersuchung journalistischen Handelns in Online-Redaktionen [Journalists on the net: A study on journalistic action in online newsrooms]. Wiesbaden: Verlag für Sozialwissenschaften.

Quandt, T. (2011). Understanding a new phenomenon: The significance of participatory journalism. In J. B. Singer (Ed.), Participatory journalism. Guarding open gates at online newspapers (pp. 155-176). Chichester: Wiley-Blackwell.

Quandt, T. (2012, March 29). Planlos in die Partizipation [Purposeless into participation]. Journalistik Journal. Retrieved from http://journalistik-journal. lookingintomedia.com/?p=815

Quandt, T., \& Festl, R. (2017). Cyberhate. In P. Rössler (Ed.), The international encyclopedia of media effects (pp. 336-344). Malden: Wiley-Blackwell.

Quandt, T., Frischlich, L., Boberg, S., \& Schatto-Eckrodt, T. (in press). Fake news. In T. P. Vos \& F. Hanusch (Eds.), The international encyclopedia of journalism studies. Malden: Wiley-Blackwell.

Rainie, L., Anderson, J., \& Albright, J. (2017, March 29). The future of free speech, trolls, anonymity and fake news online. Washington, DC: Pew Research Center. Retrieved from http://www.pewinternet.org/2017 /03/29/the-future-of-free-speech-trolls-anonymityand-fake-news-online

Rousseau, J.-J. (2018). Du contrat social, ou principes $d u$ droit politique [On the social contract; or, principles of political rights]. London: Fb\&C Ltd. (Original work published 1762)

Rowe, I. (2015). Deliberation 2.0: Comparing the deliberative quality of online news user comments across platforms. Journal of Broadcasting \& Electronic Media, 59(4), 539-555.

Rubin, V. L, Chen, Y., \& Conroy, N. J. (2015). Deception detection for news: Three types of fakes. In Proceedings of the Association for Information Science and Technology, 52(1), 1-4.

Sanovich, S. (2017). Computational propaganda in Russia: The origins of digital disinformation (Working Paper 2017.3). Oxford: Project on Computational Propaganda.

Santana, A. D. (2014). Virtuous or vitriolic: The effect of anonymity on civility in online newspaper reader comment boards. Journalism Practice, 8(1), 18-33.

Santana, A. D. (2016). Controlling the conversation: The availability of commenting forums in online newspapers. Journalism Studies, 17(2), 141-158.

Schönbach, K. (1997). Das hyperaktive Publikum: Essay über eine Illusion [The hyper-active audience: Essay on an illusion]. Publizistik, 42, 279-286.

Schönbach, K. (2001). Myths of media and audiences: Inaugural lecture as professor of general communication science, University of Amsterdam. European Journal of Communication, 16(3), 361-376.

Seely, N. (2018). Virtual vitriol: A comparative analysis of incivility within political news discussion forums. Electronic News, 12(1), 42-61.

Shakarian, P. (2011). The 2008 Russian cyber campaign against Georgia. Military Review, 91(6), 63-68.

Singer, J., Hermida, A., Domingo, D., Heinonen, A., Paulussen, S., Quandt, T., .. \& \& Vujnovic, M. (2011). Participatory journalism: Guarding open gates at online newspapers. Malden: Wiley-Blackwell.

Smith, P. K., Mahdavi, J., Carvalho, M., Fisher, S., \& Russell, S. (2008). Cyberbullying: Its nature and impact in secondary school pupils. Journal of Child Psychology and Psychiatry, 49(4), 376-385.

Stelzenmüller, C. (2017, June 28). The impact of Russian interference on Germany's 2017 elections: Testimony before the U.S. Senate Select Committee on Intelligence. Washington, DC: Brookings Institution. Retrieved from https://www.brookings.edu/ testimonies/the-impact-of-russian-interference-ongermanys-2017-elections

Steppat, T. (2014, September 8). Ich bin der Troll [I am the troll]. Frankfurter Allgemeine Zeitung. Retrieved from http://www.faz.net/aktuell/feuilleton/medien /hass-im-netz-ich-bin-der-troll-13139203.html

Su, L. Y.-F., Xenos, M. A., Rose, K. M., Wirz, C., Scheufele, D. A., \& Brossard, D. (2018). Uncivil and personal? Comparing patterns of incivility in comments on the Facebook pages of news outlets. New Media \& Society. https://doi.org/10.1177/1461444818757205

Toepfl, F., \& Piwoni, E. (2017). Targeting dominant 
publics: How counterpublic commenters align their efforts with mainstream news. New Media \& Society, 20(5), 2011-2027.

Tokunaga, R. S. (2010). Following you home from school: A critical review and synthesis of research on cyberbullying victimization. Computers in Human Behavior, 26(3), 277-287.

Vujnovic, M., Singer, J. B., Paulussen, S., Heinonen, A., Reich, Z., . . . \& Domingo, D. (2010). Exploring the political-economic factors of participatory journalism: Views of online journalists in ten countries. Journalism Practice, 4, 285-296.

Walker, S. (2015, April 2). The Russian troll factory at the heart of the meddling allegations. The Guardian. Retrieved from https://www.theguardian.com/ world/2015/apr/02/putin-kremlin-inside-russian-troll -house

Weaver, D. H., \& Gray, R. G. (1980). Journalism \& mass communication research in the United States: Past, present and future. In G. C. Wilhoit \& H. de Boek (Eds.), Mass communication review yearbook (Vol. I, pp. 124-151). Beverly Hills, CA: Sage.

Weedon, J., Nuland, W., \& Stamos, A. (2017, April 27). Information operations and Facebook. Menlo Park, CA: Facebook, Inc. Retrieved from https://fbnews roomus.files.wordpress.com/2017/04/facebook-and -information-operations-v1.pdf

Wolfgang, J. D. (2018). Taming the "trolls": How journalists negotiate the boundaries of journalism and online comments. Journalism. https://doi.org/10.1177/ 1464884918762362

Zelenkauskaite, A., \& Balduccini, M. (2017). “Information warfare" and online news commenting: Analyzing forces of social influence through location-based commenting user typology. Social Media + Society, 3(3). https://doi.org/10.1177/2056305117718468

\section{About the Author}

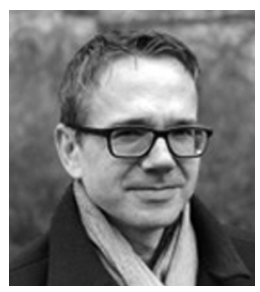

Thorsten Quandt is a Professor of Online Communication at the University of Münster, Germany. His research fields include online communication, digital games and (online) journalism. Quandt is particularly interested in the societal changes connected to the Internet and new media, and the question how human beings have evolved in sync with these changes. His earlier works on participatory journalism and online newsroom production have been widely cited in the field of (digital) journalism research. 